\title{
The implementation of small-scale hydropower stations in slow flow micro-rivers: a case study of Uzbekistan
}

\author{
Dilshod Kodirov ${ }^{1}$, Obid Tursunov ${ }^{1, *}$, Sevarakhon Parpieva ${ }^{1}$, Nusratillo Toshpulatov ${ }^{1}$, \\ Kurash Kubyashev ${ }^{1}$, Alisher Davirov" ${ }^{1}$, and Orifjon Klichov ${ }^{1}$ \\ ${ }^{1}$ Tashkent Institute of Irrigation and Agricultural Mechanization Engineers, 100000, 39, Kari \\ Niyazov, Tashkent, Uzbekistan
}

\begin{abstract}
Electric energy production in small-scale hydropower stations is attractive from both an ecological and an economical point of view. Technological innovations and measures to lessen environmental impacts make small-scale hydropower stations inexpensive and justified energy sources that provide renewable energy on an independent basis and help not only to protect the environment but also to weaken human dependence on fossil fuels. This study is devoted to finding solutions based on renewable energy technologies and innovations in Uzbekistan. This article is devoted to the development of a water wheel experimental model for the micro-hydroelectric power station. Experimental studies were carried out on the basis of this model and obtained results were used in the preliminary calculations. The results from the calculations showed that the installation can generate 7-11 kWh of electricity per hour, about $168-264 \mathrm{kWh}$ of electricity per day and 61 to $96 \mathrm{MWh}$ of electricity per year.
\end{abstract}

\section{Introduction}

One of the important problems in power engineering, except obtaining energy, is providing opportunities of its storage and transfer [1]. We are forced to repeatedly transform one type of energy to another. Each transformation is followed by losses of a part of energy. As a result, we really consume no more than a half from all received energy.

At the same time, Uzbekistan has a great potential for alternative energy sources, experts estimate that the amount of which as three times the resource of organic nonrenewable fuel. In the country, there are more than 300 sunny days a year, suitable territories, mountain rivers, which can be used to generate electricity [2]. Such rich natural opportunities should be applied to the intended purpose, be widely introduced into the practice of producing electricity based on renewable energy sources (RES). The availability of such resources is growing worldwide.

A concern in using renewable energy sources (wind, sun, bioenergetics of sea tide and waves) can be easily explained. For instance, there is no need to purchase expensive fuel. Small plants can be used to supply electricity in remote areas. The latter is especially

* Corresponding author: obidtursunov@gmail.com 
important for countries with sparsely populated areas or mountain ranges, where the construction of electricity supply network is economically unworkable.

So, in any corner of Uzbekistan there are small rivers where micro hydroelectric power station can be installed to generate electricity [3].

The modern micro hydroelectric power stations become profitable in terms of their management scheme simplification (i.e. at the expense of ballast loading) and operation without service personnel. Their effectiveness increases as a result of multi-purpose use of its constructions and also delivery of power in network. There is a need of regulation of frequency and tension during the operation of the station on the isolated loading. If the reservoir has sufficient capacity, daily and weekly regulation is provided, otherwise regulation by means of ballast loading is recommended.

The hydro unit of micro hydroelectric power station consists of the turbine, the generator and the system of automatic control. By the characterization, the used water resources of micro hydroelectric power station are divided into the following categories [4]:

1. channel or small reservoirs;

2. using high-speed energy of the undisturbed flow of the rivers;

3. using existing differences of water lines on various objects of water management - from navigable constructions to water purifying.

Use of energy of small water currents on micro hydroelectric power station is one of the most efficient directions of development of renewable energy sources (RES) in the Republic of Uzbekistan.

Micro hydroelectric power stations have the following features [5]:

1. energy is developed almost free of charge;

2. it is put into operation in short terms;

3. work, as well as other RES does not depend on prices of oil, coal and other fuel;

4. makes minimum negative impact on a surrounding medium and does not cause social problems, the bound to a big power engineering;

5. much smaller areas of flooding, dams in much smaller degree than other types of power facilities, break the normal native habitat of the person and fauna, especially if they settle down on the mountain rivers with boulder and pebble beds, and stony slopes of valleys, steady against washout and flooding;

6. long construction of expensive power line is not required;

7. the cost of the developed electric power turns out higher than on larger hydroelectric power stations.

However, as a rule, micro hydroelectric power stations are used in those places where there is no centralized power supply, and availability in receiving the electric power - one of the main conditions of development of the region and upgrading of life. When using the electric power of micro hydroelectric power station for irradiating needs, it is necessary to apply energy saving lamps for economy.

\section{Research Methods}

The purpose of this paper is to calculate a water wheel developed model of the micro-HPS for mountainous regions of the Republic of Uzbekistan.

The authors developed a water wheel experimental model for a micro-HPS (Fig.1a). Experimental studies have been carried out on the basis of this model (Fig.1b), and obtained results are used in the following preliminary calculation. 


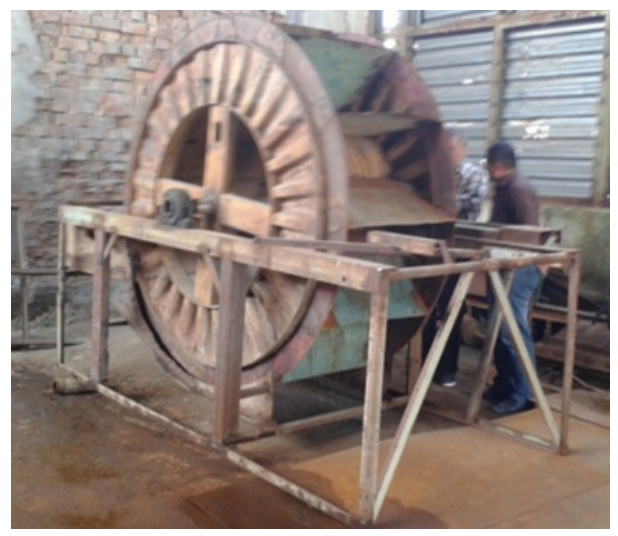

a)

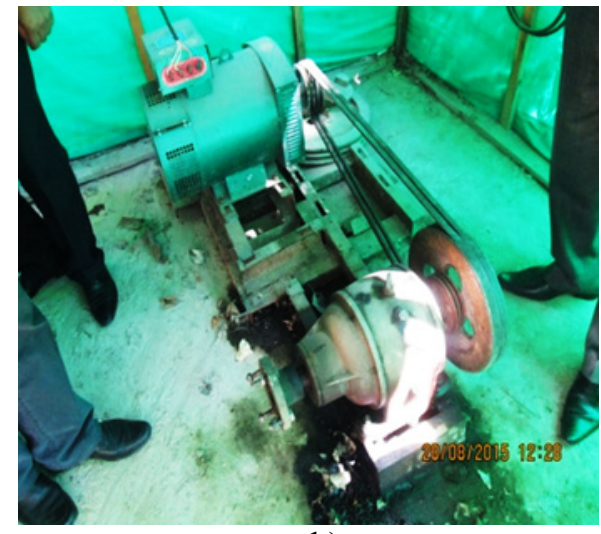

b)

Fig.1. Installation with rotating insertion (a) and installation testing process (b).

Table 1 shows the results from the annual flow rate measurements of river water flowing next to the Khamkor farm in the Kosansai district of the Namangan Region.

Table 1. HPS consumption determination.

\begin{tabular}{|c|c|c|c|c|c|c|c|c|c|c|c|c|}
\hline $\begin{array}{c}\text { Time t, } \\
\text { month }\end{array}$ & I & II & III & IV & V & VI & VII & VIII & IX & X & XI & XII \\
\hline $\begin{array}{c}\text { Consumption } \\
\mathbf{Q}, \mathrm{m}^{3} / \mathrm{s}\end{array}$ & 1,1 & 1,3 & 1,2 & 1,2 & 1,2 & 1,2 & 1,5 & 1,5 & 1,2 & 1,2 & 0,9 & 1 \\
\hline
\end{tabular}

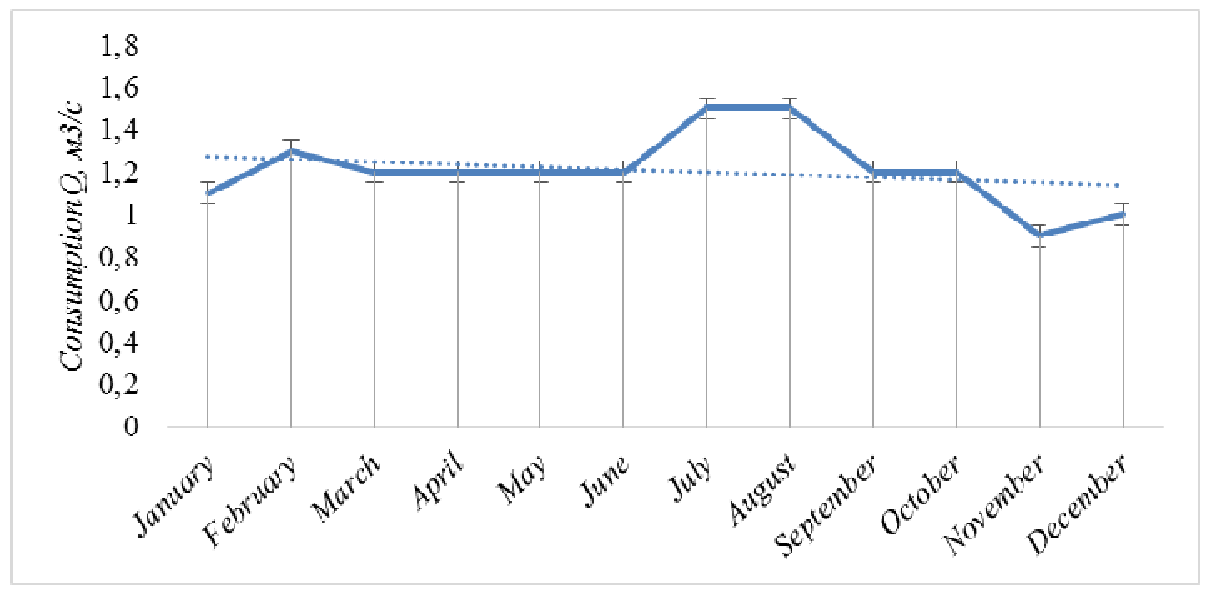

Fig. 2. Water consumption, 2018.

An amount of electricity can be determined using the following equations:

$$
N_{i}=g \cdot \eta \cdot Q_{i} \cdot H_{i}
$$

where,

$N_{i}$ - capacity, $\mathrm{kW}$;

$Q_{i}$ - water flow rate, $\mathrm{m}^{3} / \mathrm{s}$; 
$H_{i}$ - full hydrostatic head, m;

$g$ - acceleration of free fall equal to $9.8 \mathrm{~m} / \mathrm{s}$;

$\eta$ - coefficient of efficiency - 0,5 ;

\section{Results}

The obtained results for the water wheel at different water flow rates in the river are givenin Table 2 .

Table 2. Determination of average daily capacity

\begin{tabular}{|c|c|c|c|}
\hline Months & $\begin{array}{c}\text { Consumption } \\
\mathbf{Q}_{i}, \mathbf{m}^{\mathbf{3}} / \mathbf{s}\end{array}$ & $\begin{array}{c}\mathbf{H e a d} \\
\mathbf{H}_{\mathbf{i}}, \mathbf{m} \mathbf{M}\end{array}$ & $\begin{array}{c}\text { Capacity } \\
\mathbf{N i}, \mathbf{k W}\end{array}$ \\
\hline January & 1,1 & 2 & 10,8 \\
\hline February & 1,3 & 2 & 12,7 \\
\hline March & 1,2 & 2 & 11,7 \\
\hline April & 1,2 & 2 & 11,7 \\
\hline May & 1,2 & 2 & 11,7 \\
\hline June & 1,2 & 2 & 11,7 \\
\hline July & 1,5 & 2 & 14,7 \\
\hline August & 1,5 & 2 & 14,7 \\
\hline September & 1,2 & 2 & 11,7 \\
\hline October & 1,2 & 2 & 11,7 \\
\hline November & 0,9 & 2 & 8,8 \\
\hline December & 1 & 1,5 & 9,8 \\
\hline
\end{tabular}

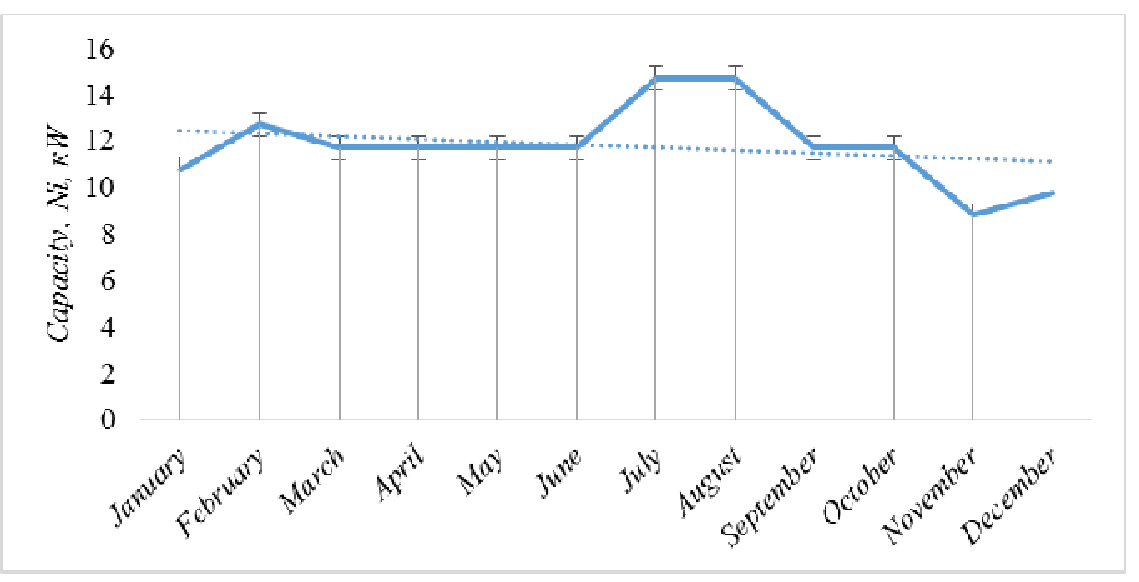

Fig. 3. Capacity received during the flow of water for one year

Table 2 shows that the capacity of the micro-HPS depends on the individual factors of local terrain. As the rate of water flow increases, a water wheel velocity increases too (Fig. $4)$, hence, the electric power of the micro-HPS increases.

The number of revolutions $n$ of the water wheel is determined by the formula [4]:

$$
n=\frac{30}{\pi} \cdot \frac{v}{R} \mathrm{rev} / \mathrm{min}
$$

where,

$v$ - flow rate in $\mathrm{m} / \mathrm{s}$.

$\mathrm{R}$ - radius of the disk in $m$, 
$\pi$ - ratio of the perimeter of the circle to its diameter $=3.14$

Table 3. Micro-HPS wheel revolution dependence on the water flow rate

\begin{tabular}{|c|c|c|c|c|c|c|c|c|c|c|c|c|}
\hline № & $\mathbf{1}$ & $\mathbf{2}$ & $\mathbf{3}$ & $\mathbf{4}$ & $\mathbf{5}$ & $\mathbf{6}$ & $\mathbf{7}$ & $\mathbf{8}$ & $\mathbf{9}$ & $\mathbf{1 0}$ & $\mathbf{1 1}$ & $\mathbf{1 2}$ \\
\hline$v(\mathrm{~m} / \mathrm{s})$ & 1 & 1,1 & 1,2 & 1,3 & 1,4 & 1,5 & 1,6 & 1,7 & 1,8 & 1,9 & 2,0 & 2,1 \\
\hline$n(\mathrm{rev} / \mathrm{min})$ & 19,1 & 21 & 22,9 & 24,8 & 26,8 & 28,7 & 30,6 & 32,5 & 34,4 & 36,3 & 38,2 & 40,1 \\
\hline
\end{tabular}

Fig.4 indicates that the velocity of the water flow is directly proportional to the capacity of the micro hydro power plant. During the experimental study, it was observed that when the velocity increases the flow rate increases as well.

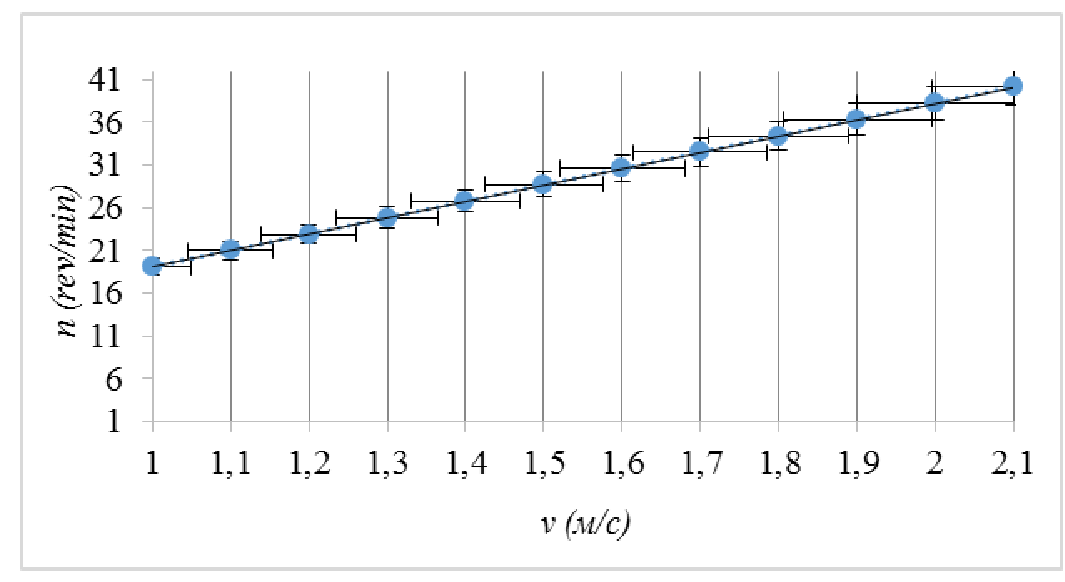

Fig. 4. Micro-HPS wheel revolution dependence on the water flow rate

The developed micro-hydroelectric power station is installed in a low-pressure watercourse (see Fig.5a), where the electric energy storage device was installed to control the energy flow (see Fig.5b).

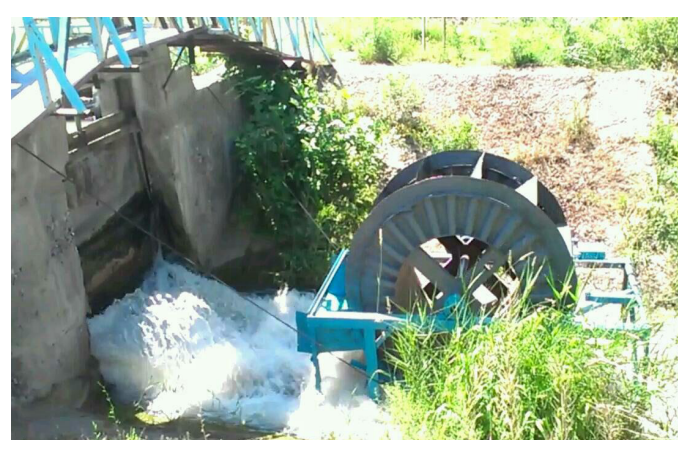

a)

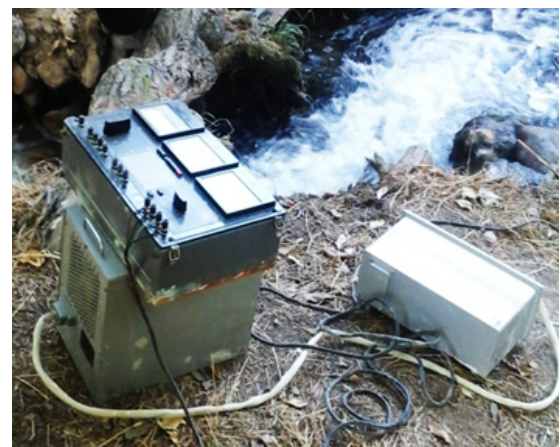

б)

Fig.5. External image of the installed water wheel (a) and the electric energy storage device (b)

To test micro hydroelectric power station, a water wheel connected to a generator using a belt drive was put into operation. The test results of the micro-hydroelectric power station are given in Table. 4 
Table 4. The test results of micro hydroelectric power station

\begin{tabular}{|c|c|c|c|}
\hline Observation numbers & $\begin{array}{c}\text { Current force, } \\
\mathbf{A}\end{array}$ & Voltage, $\mathbf{V}$ & Power, kWt \\
\hline 1 & 40,4 & 200 & 8,8 \\
\hline 2 & 41,9 & 234 & 9,8 \\
\hline 3 & 46,3 & 224 & 10,4 \\
\hline 4 & 44,45 & 207 & 9,2 \\
\hline 5 & 45,3 & 210 & 9,6 \\
\hline 6 & 40,19 & 214 & 8,6 \\
\hline
\end{tabular}

According to the research, it is inferred that if a mobile micro-HPS operates continuously, it can generate $7-11 \mathrm{kWh}$ of electricity per hour, about $168-264 \mathrm{kWh}$ of electricity per day and 61-96 MWh of electricity per year.

Determination of the payback period of micro-HPS equipment costs:

where,

$$
K=\frac{c}{N_{R} \cdot 24 \cdot 365 \cdot T} \text { year }
$$

$\mathrm{K}$ - payback period of equipment costs, year;

$\mathrm{C}$ - total equipment price, uzb soum

$\mathrm{N}_{\mathrm{n}}$ - nominal capacity of equipment, $\mathrm{kW}$

$\mathrm{T}$ - electricity price, uzb soum

The average cost of equipment $(\mathrm{C})$ is 40.0 million uzb soums. Nominal equipment capacity $\mathrm{Nn}=8.9 \mathrm{~kW}$ (Table 2 ), the price of electricity by tariffs for household consumers is 191 uzb soums [5] (February 2019 price statistics)

Based on the above, the following can be obtained:

$$
\mathrm{K}=\frac{\mathrm{C}}{\mathrm{N}_{\mathrm{B}} \cdot 24 \cdot 365 \cdot \mathrm{T}}=\frac{40,000,000}{8,9 \cdot 24 \cdot 365 \cdot 250}=2,0
$$

Hence, the developed equipment pays off in 2 years.

The preliminary calculations show that the capacity of the micro-HPS depends on the individual factors of the local terrain. As the rate of water flow increases, a water wheel velocity increases (Fig. 4); hence, the electric power of the micro-HPS increases.

\section{Conclusions}

Micro-hydroelectric power station practice has shown that small settlements can be located in any area of the country if the location, water flow and hydro-generator are selected correctly and based on the geographical capabilities of the region, and most importantly, the experience of producing different types of geometries. This new micro hydro power plant can be used by businesses and farms for their electricity consumption.

The authors submitted the application №01562 to the Agency for Intellectual Property of the Republic of Uzbekistan for obtaining a patent for a utility model of this installation.

\section{References}

1. R.A. Zakhidov, M.S. Saidov, Renewable energy at the beginning of the 21st century, the state and prospects for the development of solar technology in Uzbekistan (2009)

2. D. Khodzhaev, B. Normuminov, Y. Mustapakulov, A. Mottaeva, E3S Web of Conferences, 110, 01045, (2019) doi.org/10.1051/e3sconf /201911001045

3. D. Kodirov, Int J Energ. 12, 25-27 (2015)

4. V.N. Yurenkov, Bulletin of ALTGTU I.I. 2,143-150 (2006)

5. D. Kodirov, O. Tursunov, E3S Web of Conferences 97 , 05042 (2019) 